\title{
Changes in small intestinal chromogranin A-immunoreactive cell densities in patients with irritable bowel syndrome after receiving dietary guidance
}

\author{
TAREK MAZZAWI $^{1,3}$ and MAGDY EL-SALHY ${ }^{2,3}$ \\ ${ }^{1}$ Division of Gastroenterology, Department of Clinical Medicine, University of Bergen, Bergen; \\ ${ }^{2}$ Division of Gastroenterology, Department of Medicine, Stord Hospital-Helse Fonna, Stord; \\ ${ }^{3}$ National Centre for Functional Gastrointestinal Disorders, Department of Medicine, \\ Haukeland University Hospital-Helse Bergen, Bergen, Norway
}

Received November 23, 2015; Accepted February 17, 2016

DOI: $10.3892 /$ ijmm.2016.2523

\begin{abstract}
Chromogranin A $(\mathrm{CgA})$ is a common marker for enteroendocrine cells in the gut, and $\mathrm{CgA}$-immunoreactive cell densities are abnormal in patients with irritable bowel syndrome (IBS). The majority of patients with IBS report that their symptoms develop after consuming certain foodstuffs. In the present study, we investigated the effects of dietary guidance on the total enteroendocrine cell densities in the small intestine, as detected by $\mathrm{CgA}$. A total of 14 patients with IBS underwent a gastroscopy with duodenal biopsies and 11 of them also underwent a colonoscopy, with biopsy samples obtained from the ileum. Fourteen control subjects were also included. Each patient received 3 sessions of dietary guidance. Gastroscopies and colonoscopies were performed on both the controls and patients with IBS (at baseline and at 3-9 months after receiving guidance). Biopsy samples obtained from the duodenum and ileum were immunostained for $\mathrm{CgA}$ using the avidin-biotin complex $(\mathrm{ABC})$ method and were quantified using computerized image analysis. The density of $\mathrm{CgA}$-immunoreactive cells in the duodenum (mean \pm SEM values) in the control subjects was $235.9 \pm 31.9$ cells $/ \mathrm{mm}^{2}$; in the patients with IBS, the density was $36.9 \pm 9.8$ and $103.7 \pm 16.9$ cells $/ \mathrm{mm}^{2}$ before and after they received dietary guidance, respectively $(\mathrm{P}=0.007)$. The density of $\mathrm{CgA}$-immunoreactive cells in the ileum in the control subjects was $47.4 \pm 8.3$ cells $/ \mathrm{mm}^{2}$; in the patients with IBS, the density was $48.4 \pm 8.1$ and $17.9 \pm 4.4$ cells $/ \mathrm{mm}^{2}$, before and after they received dietary guidance, respectively $(\mathrm{P}=0.0006)$. These data indicate that changes in $\mathrm{CgA}$-immunoreactive cell densi-
\end{abstract}

Correspondence to: Dr Tarek Mazzawi, Division of Gastroenterology, Department of Medicine, Haukeland University Hospital, Jonas Lies vei 65, 5021 Bergen, Norway

E-mail: tarek.ramzi.elia.mazzawi@helse-bergen.no tarek.mazzawi@gmail.com

Key words: irritable bowel syndrome, computerized image analysis, diet, enteroendocrine cells, small intestine, immunohistochemistry, chromogranin A ties in patients with IBS after receiving dietary guidance may reflect a change in the densities of the small intestinal enteroendocrine cells, which may contribute to an improvement in the IBS symptoms.

\section{Introduction}

Irritable bowel syndrome (IBS) is a common chronic gastrointestinal (GI) disorder with a complex pathogenesis (1). Multiple factors contribute to the development of IBS, such as diet, an altered neuroendocrine system, intestinal microbiota, lowgrade mucosal inflammation and genetics (2). The majority of patients with IBS report that their symptoms develop after consuming certain foodstuffs (3-5), most commonly fermentable oligosaccharides, disaccharides, monosaccharides and polyols (FODMAPs) (6-8).

The types of enteroendocrine cells differ between the proximal and distal parts of the small intestine (9). The duodenum harbors a large number of different enteroendocrine cells, such as those related to serotonin, somatostatin, cholecystokinin, secretin and gastric inhibitory peptide, whereas the ileum contains serotonin, peptide YY, pancreatic polypeptide, oxyntomodulin (enteroglucagon) and somatostatin $(10,11)$.

Chromogranin A $(\mathrm{CgA})$ is a common marker of enteroendocrine cells in the gut (12-14). Patients with IBS reportedly have abnormal densities of $\mathrm{CgA}$-immunoreactive cells throughout the different sections of the GI tract (15-19). Providing patients with IBS with dietary guidance regarding the consumption of a low-FODMAP diet has been found to improve their symptoms and quality of life (20) and to normalize the densities of several enteroendocrine cell types in their stomach $(21,22)$ and colon $(23,24)$. Thus, the present study was undertaken to investigate the effects of dietary guidance on the total population of enteroendocrine cells in the small intestine (duodenum and ileum) as detected by $\mathrm{CgA}$ in the same cohort of patients with IBS.

\section{Subjects and methods}

Patients and controls. Patients of both genders aged between 18 and 70 years who were referred to the Division of 
Gastroenterology, Stord Hospital, Stord, Norway and fulfilled Rome-III criteria for the diagnosis of IBS were included in this study. The exclusion criteria included pregnant or lactating women, and patients with serious psychiatric or any organic/systemic diseases, drug abuse, or previous abdominal surgery, with the exception of appendectomy, caesarean section and hysterectomy.

A control group of 14 subjects comprising 9 females and 5 males with a mean age of 54 years (range, 26-70 years) was included in this study. The control group subjects had no symptoms related to IBS and they were found from subjects presenting with health concerns not related to IBS. Four subjects in the control group underwent endoscopies due to GI bleeding where the source was identified as hemorrhoids $(n=3)$ or angiodysplasia $(n=1)$; the other 10 subjects in the control group had health concerns caused by family members being diagnosed with cancer of the GI tract.

The study was performed in accordance with the Declaration ofHelsinkiand was approved by the LocalCommittee for Medical Research Ethics West, Bergen, Norway (no. 2010/2650-2). All patients and control subjects provided both oral and written consent prior to participating in the study.

Study design. Forty-six patients (35 females and 11 males) with a mean age of 35 years (range, 18-69 years) were enrolled in this study. All the patients underwent physical examinations and blood tests, including CBC, C-reactive protein, antinuclear antibody (ANA), electrolytes, creatinine, and thyroid and liver function tests were performed to exclude the presence of inflammation, infection and other organic diseases. The patients were scheduled to receive 3 sessions ( 45 min each) of individualized dietary guidance from a nurse experienced in diet and IBS, with the sessions separated by intervals of at least 2 weeks (Fig. 1). The individualized dietary guidance has been previously explained in detail in our previous studies (20-24). Briefly, the first session focused on delivering general information about IBS, regular and healthy eating habits and on foodstuffs that aggravate IBS symptoms, such as insoluble dietary fiber and poorly absorbable FODMAPs. The patients were told to alternate between consuming diets that were rich and poor in proteins, fats and carbohydrates, each for 3-4 days, for a total period of 2 weeks. The daily consumption of food and fluids along with any associated symptoms (frequency and degree of abdominal pain and abdominal distension) and the frequency and consistency of the stool were registered in a daily diary. No food supplements containing probiotics, antibiotics and other medications were allowed during the study unless otherwise specified. In the second session, the patients were instructed to alter the proportions of proteins, fats and carbohydrates in their diet and to avoid foodstuffs (including vegetables and fruits) that are rich in FODMAPs or insoluble fiber, and to consume foodstuffs that contained lower amounts of FODMAPs and insoluble fiber. During the third session, each patient gave feedback about the dietary guidance, and a suitable diet was designed for the patient to follow until the end of the study.

The patients were examined with gastroscopies and colonoscopies before the first session (baseline) and at 3-9 months (median, 4 months) following the third session of dietary guidance.
Dietary assessment. Dietary intake was assessed using the MoBa food frequency questionnaire (MoBa FFQ). Responses to this questionnaire report the frequency and the portion sizes of food meals and beverages consumed over a defined period of time. Data analysis was conducted using software to calculate the nutrient content of the diet. The MoBa FFQ was developed and validated by the Norwegian Institute of Public Health in Oslo, Norway $(25,26)$. This questionnaire inquires about the consumption of 225 foodstuffs and identifies the dietary habits of the participant, including the intake of any oral supplements, according to typical Norwegian meal patterns. The patients completed the MoBa FFQ form before the first session and again at least 3 months after the third session of individualized dietary guidance, which was delivered at the same day when the endoscopy was scheduled, as previously described (20).

Endoscopies. The control subjects and patients fasted overnight and used Picoprep ${ }^{\circledR}$ (Ferring Pharmaceuticals, Saint-Prex, Switzerland) for bowel preparation the day before the endoscopies were performed. During gastroscopy, 4 biopsy samples were obtained from the descending part of the duodenum, distal to the papilla of Vater. Four biopsy samples were also taken from the ileum during the colonoscopy examination of each subject.

Histopathology and immunohistochemistry. The enteroendocrine cells are present on the surface facing the lumen and mostly in the crypts. All the 4 biopsy samples were fixed overnight in $4 \%$ buffered paraformaldehyde, embedded in paraffin and sectioned at a thickness of $5 \mu \mathrm{m}$. Each slide consisted of 2 sections taken $50 \mu \mathrm{m}$ apart (related to their position in the biopsied tissue sample), thus ensuring to have included slices from the entire mucosa and not just the surface. The sections were stained with hematoxylin and eosin and immunostained using the avidin-biotin complex (ABC) method with the Vectastain $\mathrm{ABC}$ kit and the chromogen 3,3'-diaminobenzidine (DAB) peroxidase substrate kit (both from Vector Laboratories, Burlingame, CA, USA) as previously described (27). The primary monoclonal mouse antibody raised against the $\mathrm{N}$-terminal of purified CgA (code no. M0869; Dako, Glostrup, Denmark) was diluted to 1:1,000. The sections were then hydrated and immersed in $0.01 \%$ hydrogen peroxide in phosphate-buffered saline (PBS; $\mathrm{pH} 7.4$ ) for $10 \mathrm{~min}$ to inhibit endogenous peroxidase activity. After washing in buffer, the sections were treated with $1 \%$ bovine serum albumin for $30 \mathrm{~min}$ to block non-specific binding sites and then incubated at room temperature for $1 \mathrm{~h}$ with the primary antibody. The sections were then washed in PBS and incubated at room temperature for $30 \mathrm{~min}$ with biotinylated swine antimouse IgG (Dako) diluted to 1:200. After washing the slides in PBS, the sections were incubated for $30 \mathrm{~min}$ with avidin-biotin-peroxidase complex diluted to 1:100 and then submerged in DAB followed by counterstaining with hematoxylin.

Computer image analysis. The density of CgA-immunoreactive cells in the duodenum and ileum of patients with IBS and the controls was measured using Olympus Cell^D software (Olympus, Tokyo, Japan). The number of CgA-immunoreactive cells and the area of the epithelial cells were measured in 


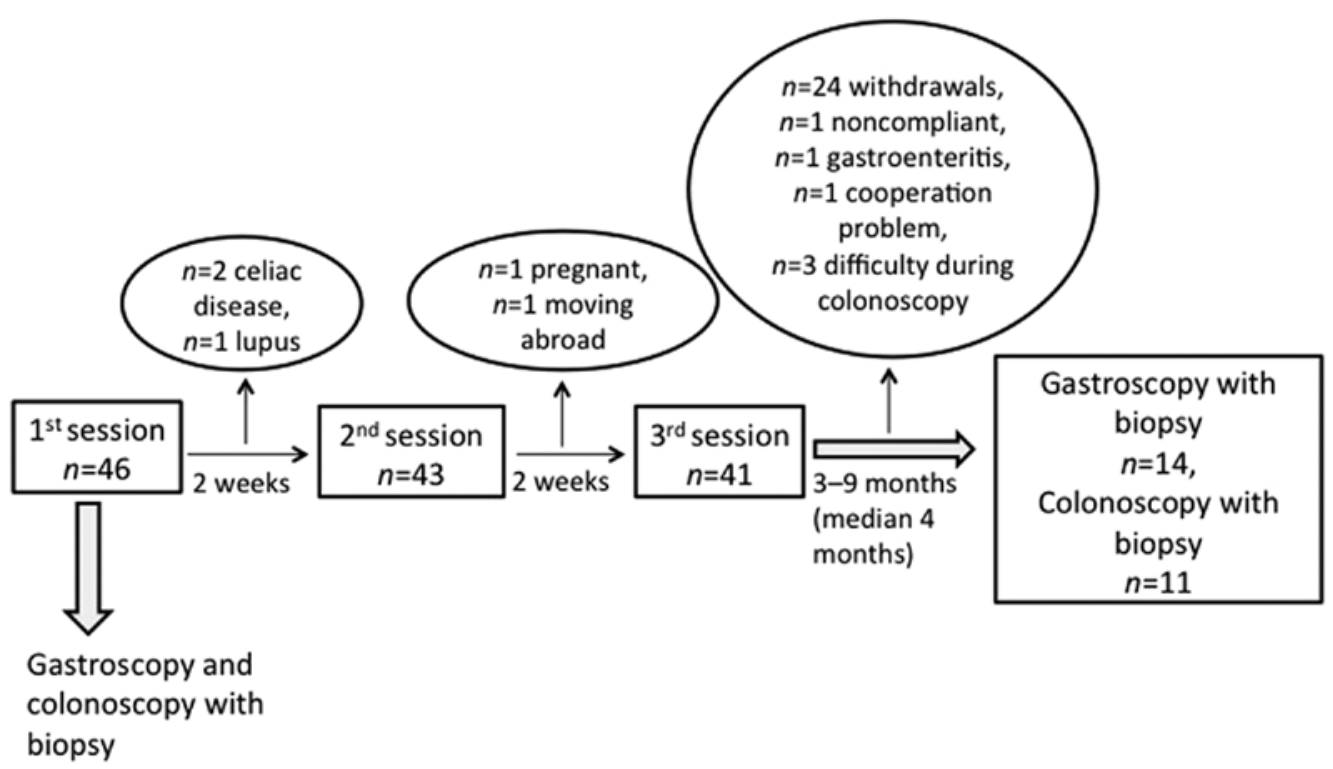

Figure 1. Study flow chart.

10 randomly selected fields per slide, at magnification of $x 40$; at this magnification, each field represents a tissue area of $0.14 \mathrm{~mm}^{2}$. The data from the fields were tabulated and the density of $\mathrm{CgA}$-immunoreactive cells, expressed as the number of cells per square millimeter of the epithelium, was computed and analyzed statistically. All quantification was conducted by the same scientist (Dr Tarek Mazzawi) who was blinded to the identity of the sections.

Statistical analysis. Statistical analyses [95\% confidence interval (CI) and P-value] were conducted using the program GraphPad Prism 6. The Kruskal-Wallis non-parametric test, with Dunn's test as a post-test was used to make comparisons between the control subjects and patients with IBS before dietary guidance, and between the control subjects and patients with IBS after dietary guidance. The paired t-test was used to compare the results obtained from the patients before and after they received dietary guidance. The data are presented as the mean \pm SEM values. A probability value of $\mathrm{P}<0.05$ was considered to indicate a statistically significant difference.

\section{Results}

Patients and control subjects. Forty-six patients were included in this study and they received sessions of individualized dietary guidance. The study flow chart presented in Fig. 1 shows that several patients did not complete the study for different reasons, namely due to newly diagnosed celiac disease $(n=2)$ or lupus $(n=1)$, cooperation issues $(n=1)$, noncompliance $(n=1)$, pregnancy $(n=1)$, moving abroad $(n=1)$, receiving antibiotics due to gastroenteritis $(n=1)$ and the withdrawal of consent $(n=24)$. Thus, 14 of the original 46 patients with IBS completed the entire study, comprising 9 females and 5 males with a mean age of 33 years (range, 21-44 years). In 3 patients ( 2 females and 1 male) it was technically difficult to intubate the ileocecal valve during colonoscopy; thus only 11 patients ( 7 females and 4 males) with a mean age of 33 years (range, 24-44 years) underwent the second colonoscopy examination with biopsy sampling.

Six of the patients who completed the study used one or more of the following: proton-pump inhibitors $(n=4)$, thyroxin substitution tablets $(n=2)$, asthma inhalators $(n=1)$, angiotensin II receptor antagonist tablets against hypertension $(n=1)$, antiallergy tablets $(n=3)$, contraceptive pills $(n=2)$, and antidepressants/anxiolytics $(n=2)$. These patients were instructed not to take any type of proton-pump inhibitor or antacids starting from 1 week before the study and for the duration of the study.

All the 14 subjects in the control group underwent a gastroscopy with biopsy samples obtained from the duodenum in the same manner as for the patients with IBS. In 4 of these 14 subjects ( 2 males and 2 females) it was difficult to intubate the ileocecal valve, and thus biopsy samples were collected from the ileum only for 10 control subjects ( 3 males and 7 females), who had a mean age of 51 years (range, 26-70 years).

Dietary assessment. The change in diet implemented in the present study has been described in detail elsewhere (20). In brief, the daily total consumption of fruits and vegetables rich in FODMAPs decreased significantly from $16.2 \pm 5.3 \mathrm{~g}$ before receiving dietary guidance to $9.2 \pm 3.2 \mathrm{~g}$ after receiving dietary guidance $(\mathrm{P}=0.02)$. However, no significant change was observed in the daily consumption of fiber before $(27.4 \pm 2.5 \mathrm{~g})$ and after $(23.1 \pm 2.2 \mathrm{~g})$ receiving dietary guidance $(\mathrm{P}=0.09)$, as previously described (20).

Endoscopy, histopathology and immunohistochemistry. The gastroscopies and colonoscopies indicated that the duodenum and ileum were normal both macroscopically (data not shown) and microscopically in both patients with IBS and the control subjects. CgA-immunoreactive cells were found in the mucosa of both the duodenum and ileum (mostly crypts) of the patients with IBS and the control subjects. These cells were either basket- or flask-shaped, and sometimes exhibited a long basal cytoplasmic process (Figs. 3 and 5). 
Table I. Densities of chromogranin A-immunoreactive cells in the duodenum and ileum of the control subjects and patients with IBS before and after receiving dietary guidance.

\begin{tabular}{|c|c|c|c|c|c|c|}
\hline \multirow[b]{3}{*}{ Location } & \multicolumn{3}{|c|}{ Endocrine cell densities (cells $/ \mathrm{mm}^{2}$ ) } & \multirow[b]{3}{*}{${ }^{a}$ P-value } & \multirow[b]{3}{*}{${ }^{\text {bP-value }}$} & \multirow[b]{3}{*}{${ }^{\mathrm{c}} \mathrm{P}$-value } \\
\hline & \multirow[b]{2}{*}{ Controls } & \multicolumn{2}{|c|}{ Patients } & & & \\
\hline & & Before guidance & After guidance & & & \\
\hline Duodenum & $235.9 \pm 31.9$ & $36.9 \pm 9.8$ & $103.7 \pm 16.9$ & $<0.0001^{\mathrm{g}}$ & $0.03^{\mathrm{d}}$ & $0.007^{\mathrm{e}}$ \\
\hline Ileum & $47.4 \pm 8.3$ & $48.4 \pm 8.1$ & $17.9 \pm 4.4$ & 0.99 & $0.009^{\mathrm{e}}$ & $0.0006^{\mathrm{f}}$ \\
\hline
\end{tabular}

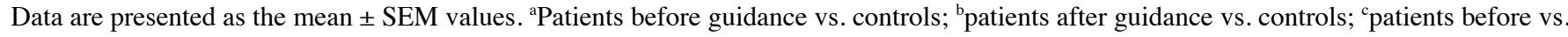
after guidance. ${ }^{\mathrm{d}} \mathrm{P}<0.05,{ }^{\mathrm{e}} \mathrm{P}<0.01,{ }^{\mathrm{f}} \mathrm{P}<0.001$ and ${ }^{\mathrm{g}} \mathrm{P}<0.0001$.

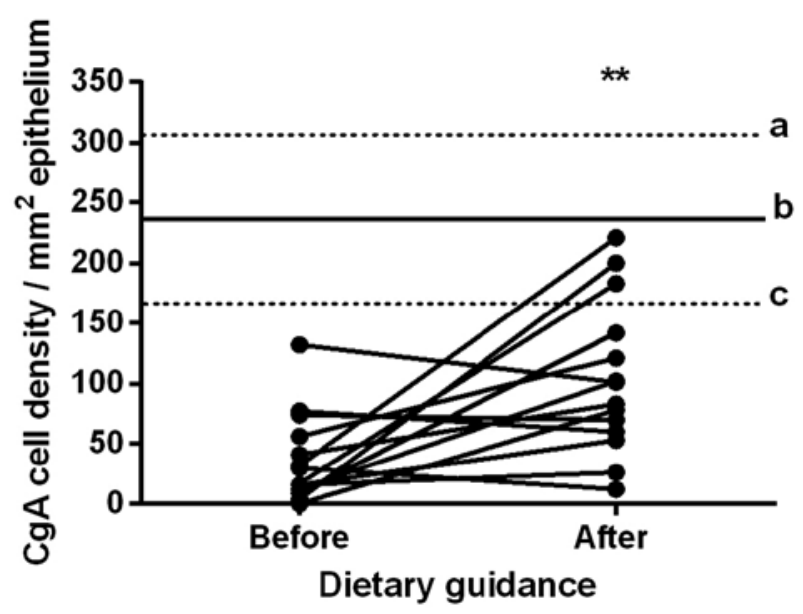

Figure 2. Chromogranin A (CgA)-immunoreactive cell densities in the duodenum in patients with irritable bowel syndrome (IBS) before and after receiving dietary guidance. The dashed lines labeled ' $a$ ' and 'c' indicate the upper and lower limits of the $95 \%$ confidence interval of the $\mathrm{CgA}$-immunoreactive cell density in the control subjects, respectively, while line ' $b$ ' indicates the mean density. ${ }^{* *} \mathrm{P}<0.01$.

\section{Computerized image analysis}

Duodenum. The densities of CgA-immunoreactive cells in the duodenum in the control subjects and in the patients with IBS before and after they received dietary guidance are listed in Table I and illustrated in Figs. 2 and 3. The paired t-test indicated that the density of $\mathrm{CgA}$-immunoreactive cells in the duodenum in the patients with IBS increased significantly after they had received dietary guidance $(\mathrm{P}=0.007)$.

Ileum. The densities of $\mathrm{CgA}$-immunoreactive cells in the ileum in the control subjects, and in the patients with IBS before and after they received dietary guidance are listed in Table I and illustrated in Figs. 4 and 5. The paired t-test indicated that the density of CgA-immunoreactive cells in the ileum in the patients with IBS decreased significantly after they had received dietary guidance $(\mathrm{P}=0.0006)$.

\section{Discussion}

Clinical studies involving patients with IBS often have high drop-out rates, reportedly ranging between 33 and 48\% (28-32), and this was also the case for the present study. The drop-out rate in the present study was $76 \%$. Twenty-four patients $(52 \%)$

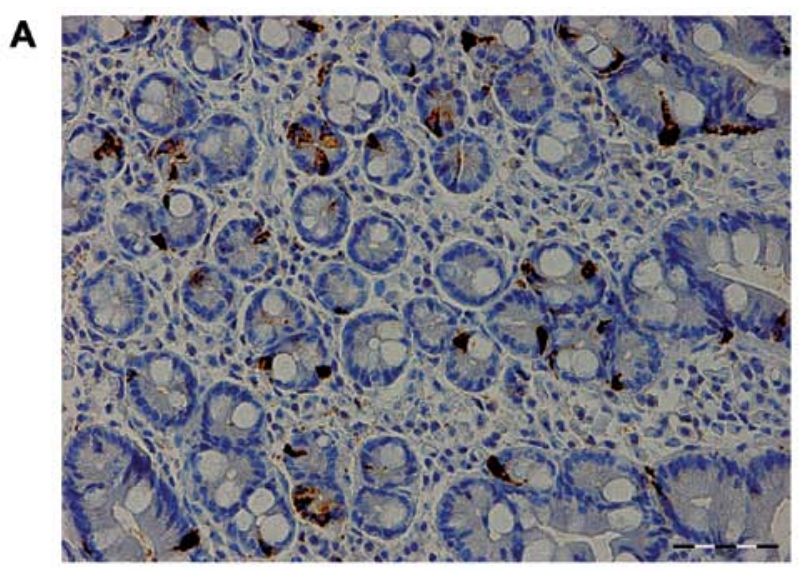

B

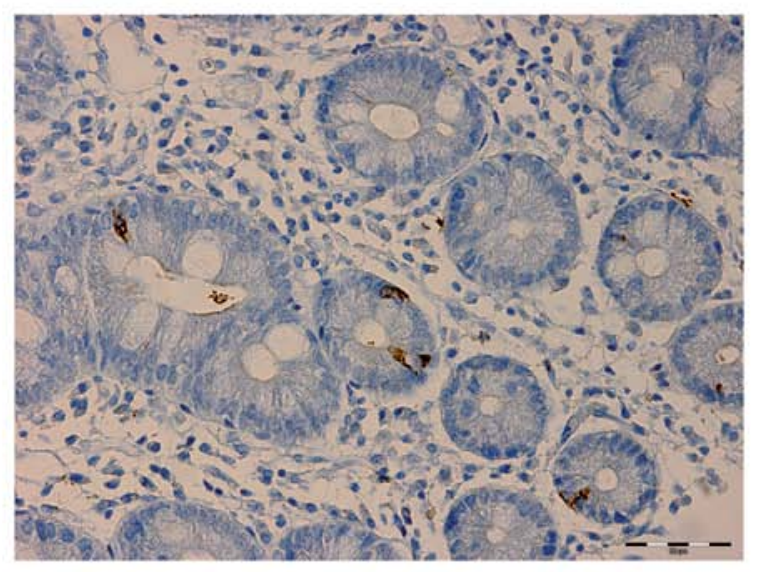

C

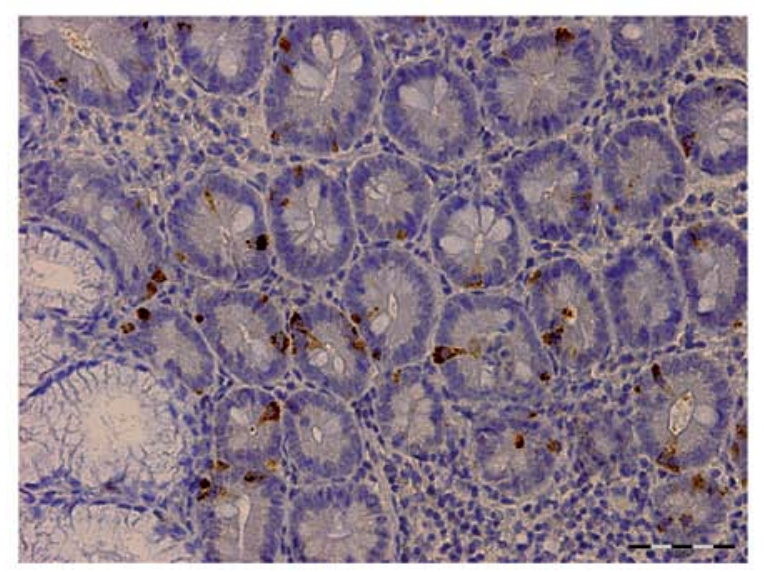

Figure 3. Chromogranin A (CgA)-immunoreactive cells in the duodenum of (A) a control subject, and of a patient with irritable bowel syndrome (IBS) (B) before and (C) after receiving dietary guidance. 


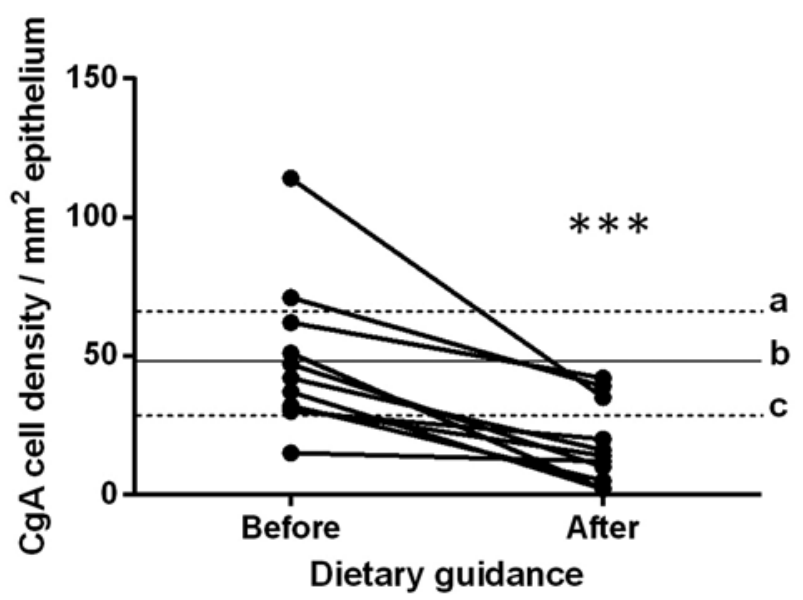

Figure 4. Chromogranin A (CgA)-immunoreactive cell densities in the ileum in patients with irritable bowel syndrome (IBS) before and after receiving dietary guidance. The dashed lines labeled ' $a$ ' and ' $c$ ' indicate the upper and lower limits of the $95 \%$ confidence interval of the CgA-immunoreactive cell density in the control subjects, respectively, while line ' $b$ ' indicates the mean density. ${ }^{* * * *} \mathrm{P}<0.001$.

out of the total number of patients included in this study $(n=46)$ were unwilling to complete the whole study and withdrew their consents due to the complexity of the study, including 2 gastroscopies and 2 colonoscopies and following a strict diet for at least 3 months. In addition, 11 patients (24\%) were excluded due to different reasons (celiac disease, lupus, pregnancy, moving abroad, noncompliance, gastroenteritis and technical difficulties encountered when performing colonoscopies).

$\mathrm{CgA}$ is a member of the granin (chromogranin-secretogranin) family located within the vesicles of neurons and endocrine cells $(12,13,33)$. The biological function of $\mathrm{CgA}$ is not yet completely known (14). CgA and its derived peptides may act as modulators of cells and tissues associated with inflammation (34). $\mathrm{CgA}$ serves as a marker for the enteroendocrine cells and endocrine tumors (12-14,17). Thus, the changes in CgA cell densities reflect changes in the total number of enteroendocrine cells. The increase or decrease in $\mathrm{CgA}$ cell densities signifies changes in the densities of one or different enteroendocrine cells in the respective segment of the small intestine. The densities of CgA-immunoreactive cells have been previously reported to be abnormal in the duodenum (17) and ileum (19) of patients with IBS, which is consistent with our findings obtained from the patients before receiving dietary guidance. The densities of the $\mathrm{CgA}$-immunoreactive cells in the small intestine (duodenum and ileum) changed significantly after the patients received dietary guidance, with the values moving toward those measured in the duodenum in the control subjects.

There are at least 15 types of enteroendocrine cells in the gut, which constitute part of the neuroendocrine system $(10,35)$. The enteroendocrine cells project microvilli into the lumen of the gut and regulate the functions of the GI tract by releasing specific hormones, depending on the sensed luminal contents (36-48). The main luminal contents that trigger the enteroendocrine cells in the gut are the nutrients $(1,49)$. Mature enteroendocrine cells differentiate from stem cells after 2-6 days $(50,51)$, and the densities of stem cells in the duodenum is lower in IBS patients than in healthy controls (52).
A

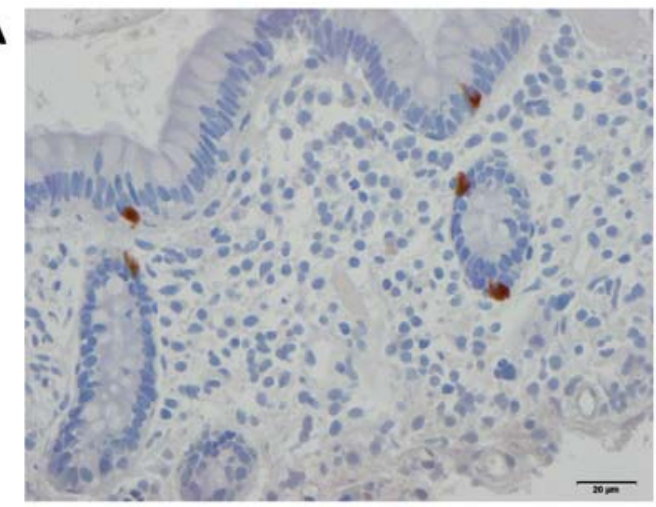

B

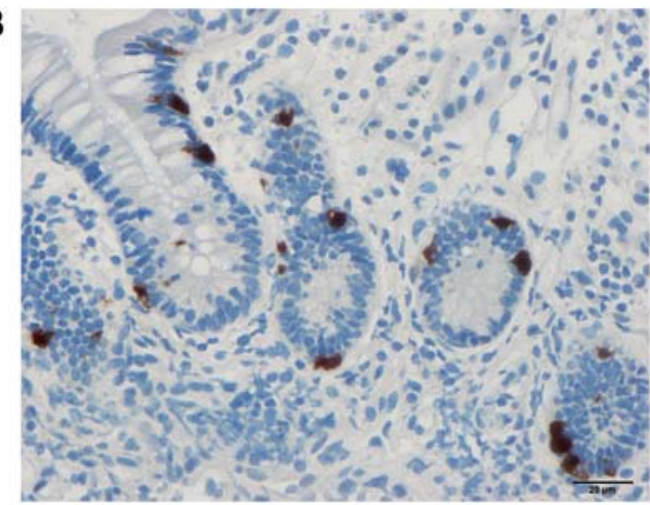

C

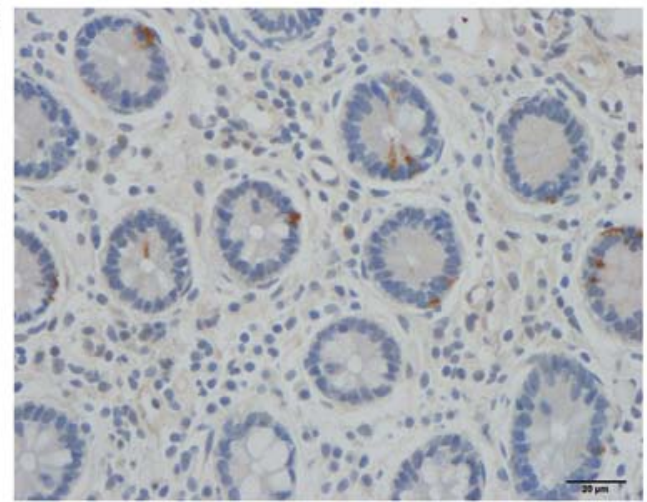

Figure 5. Chromogranin A (CgA)-immunoreactive cells in the ileum of (A) a control subject, and in a patient with irritable bowel syndrome (IBS) (B) before and (C) after receiving dietary guidance.

It can be speculated that changing the diet through guidance, resulting in improvement in IBS symptoms, as shown in an earlier study on the same cohort of IBS patients (20), can alter the differentiation of enteroendocrine cells and may explain the observed changes in the $\mathrm{CgA}$-immunoreactive cell densities in the small intestine. This interaction between diet and enteroendocrine cells is a dynamic process (53). The enteroendocrine cells regulate motility, abdominal visceral sensitivity, secretion, absorption, cell proliferation, local immune defense and appetite (1). The symptoms associated with IBS appear to be caused by GI dysmotility, visceral hypersensitivity and abnormal intestinal secretion (1). As mentioned above, motility, visceral sensitivity and secretion are regulated by the enteroendocrine cells in the gut.

To the best of our knowledge, the present study is the first to demonstrate that diet can alter the densities of enteroendocrine cells in the small intestine, in a manner similar to that observed 
in the stomach $(21,22)$ and large intestine $(23,24)$, which may have contributed to the improvement in the IBS symptoms (20). The results also highlight the involvement of the enteroendocrine cells in the gut in the pathophysiology of IBS. The change in the $\mathrm{CgA}$-immunoreactive cell densities after receiving dietary guidance may reflect a change in the densities of the small intestinal enteroendocrine cells. However, future studies are warranted to determine the actual types of enteroendocrine cell that are affected in IBS.

\section{Acknowledgements}

The present study was financially supported by a grant from Helse-Fonna (40415).

\section{References}

1. El-Salhy M, Gundersen D, Gilja OH, Hatlebakk JG and Hausken T: Is irritable bowel syndrome an organic disorder? World J Gastroenterol 20: 384-400, 2014.

2. El-Salhy M, Gundersen D, Hatlebakk JG and Hausken T: Irritable bowel syndrome. Nova Science Publisher, New York, NY, pp1-160, 2012.

3. Simrén M, Månsson A, Langkilde AM, Svedlund J, Abrahamsson H, Bengtsson U and Björnsson ES: Food-related gastrointestinal symptoms in the irritable bowel syndrome. Digestion 63: 108-115, 2001.

4. Monsbakken KW, Vandvik PO and Farup PG: Perceived food intolerance in subjects with irritable bowel syndrome - etiology, prevalence and consequences. Eur J Clin Nutr 60: 667-672, 2006.

5. Williams EA, Nai X and Corfe BM: Dietary intakes in people with irritable bowel syndrome. BMC Gastroenterol 11: 9, 2011.

6. Gibson PR, Barrett JS and Muir JG: Functional bowel symptoms and diet. Intern Med J 43: 1067-1074, 2013.

7. Gibson PR, Newnham E, Barrett JS, Shepherd SJ and Muir JG: Review article: fructose malabsorption and the bigger picture. Aliment Pharmacol Ther 25: 349-363, 2007.

8. Gibson PR and Shepherd SJ: Evidence-based dietary management of functional gastrointestinal symptoms: the FODMAP approach. J Gastroenterol Hepatol 25: 252-258, 2010.

9. Gunawardene AR, Corfe BM and Staton CA: Classification and functions of enteroendocrine cells of the lower gastrointestinal tract. Int J Exp Pathol 92: 219-231, 2011.

10. Rindi G, Leiter AB, Kopin AS, Bordi C and Solcia E: The 'normal' endocrine cell of the gut: changing concepts and new evidences. Ann N Y Acad Sci 1014: 1-12, 2004.

11. Polak JM, Coulling I, Bloom S and Pearse AG: Immunofluorescent localization of secretin and enteroglucagon in human intestinal mucosa. Scand J Gastroenterol 6: 739-744, 1971.

12. Taupenot L, Harper KL and O'Connor DT: The chromogranin-secretogranin family. N Engl J Med 348: 1134-1149, 2003.

13. Wiedenmann B and Huttner WB: Synaptophysin and chromogranins/secretogranins - widespread constituents of distinct types of neuroendocrine vesicles and new tools in tumor diagnosis. Virchows Arch B Cell Pathol Incl Mol Pathol 58: 95-121, 1989.

14. Deftos LJ: Chromogranin A: its role in endocrine function and as an endocrine and neuroendocrine tumor marker. Endocr Rev 12 181-187, 1991.

15. El-Salhy M, Gilja OH, Gundersen D, Hatlebakk JG and Hausken T: Duodenal chromogranin a cell density as a biomarker for the diagnosis of irritable bowel syndrome. Gastroenterol Res Pract 2014: 462856, 2014.

16. El-Salhy M, Gilja OH and Hausken T: Chromogranin A cells in the stomachs of patients with sporadic irritable bowel syndrome. Mol Med Rep 10: 1753-1757, 2014.

17. El-Salhy M, Lomholt-Beck B and Hausken T: Chromogranin A as a possible tool in the diagnosis of irritable bowel syndrome. Scand J Gastroenterol 45: 1435-1439, 2010.

18. El-Salhy M, Mazzawi T, Gundersen D and Hausken T: Chromogranin A cell density in the rectum of patients with irritable bowel syndrome. Mol Med Rep 6: 1223-1225, 2012.

19. El-Salhy M, Wendelbo IH and Gundersen D: Reduced chromogranin A cell density in the ileum of patients with irritable bowel syndrome. Mol Med Rep 7: 1241-1244, 2013.
20. Mazzawi T, Hausken T, Gundersen D and El-Salhy M: Effects of dietary guidance on the symptoms, quality of life and habitual dietary intake of patients with irritable bowel syndrome. Mol Med Rep 8: 845-852, 2013.

21. Mazzawi T, Hausken T, Gundersen D and El-Salhy M: Effect of dietary management on the gastric endocrine cells in patients with irritable bowel syndrome. Eur J Clin Nutr 69: 519-524, 2015.

22. Mazzawi T, Gundersen D, Hausken T and El-Salhy M: Increased gastric chromogranin A cell density following changes to diets of patients with irritable bowel syndrome. Mol Med Rep 10: 2322-2326, 2014.

23. Mazzawi T, Gundersen D, Hausken T and El-Salhy M: Increased chromogranin a cell density in the large intestine of patients with irritable bowel syndrome after receiving dietary guidance. Gastroenterol Res Pract 2015: 823897, 2015.

24. Mazzawi T, Hausken T, Gundersen D and El-Salhy M: Dietary guidance normalizes large intestinal endocrine cells densities in patients with irritable bowel syndrome. Eur J Clin Nutr 70: 175-181, 2016.

25. Masson LF, McNeill G, Tomany JO, Simpson JA, Peace HS, Wei L, Grubb DA and Bolton-Smith C: Statistical approaches for assessing the relative validity of a food-frequency questionnaire: use of correlation coefficients and the kappa statistic. Public Health Nutr 6: 313-321, 2003.

26. Brantsaeter AL, Haugen M, Alexander J and Meltzer HM: Validity of a new food frequency questionnaire for pregnant women in the Norwegian Mother and Child Cohort Study (MoBa). Matern Child Nutr 4: 28-43, 2008.

27. El-Salhy M, Stenling R and Grimelius L: Peptidergic innervation and endocrine cells in the human liver. Scand J Gastroenterol 28: 809-815, 1993.

28. Enck P, Klosterhalfen S and Kruis W: Determination of placebo effect in irritable bowel syndrome. Deutsche medizinische Wochenschrift (1946) 130: 1934-1937, 2005 (In German).

29. Ostgaard H, Hausken T, Gundersen D and El-Salhy M: Diet and effects of diet management on quality of life and symptoms in patients with irritable bowel syndrome. Mol Med Rep 5: 1382-1390, 2012

30. Abdul-Baki H, El Hajj II, Elzahabi L, Azar C, Aoun E, Skoury A, Chaar $\mathrm{H}$ and Sharara AI: A randomized controlled trial of imipramine in patients with irritable bowel syndrome. World J Gastroenterol 15: 3636-3642, 2009.

31. Zernicke KA, Campbell TS, Blustein PK, Fung TS, Johnson JA, Bacon SL and Carlson LE: Mindfulness-based stress reduction for the treatment of irritable bowel syndrome symptoms: a randomized wait-list controlled trial. Int J Behav Med 20: 385-396, 2013.

32. Halmos EP, Power VA, Shepherd SJ, Gibson PR and Muir JG: A diet low in FODMAPs reduces symptoms of irritable bowel syndrome. Gastroenterology 146: 67-75.e5, 2014.

33. Khan WI and Ghia JE: Gut hormones: Emerging role in immune activation and inflammation. Clin Exp Immunol 161: 19-27, 2010.

34. Helle KB: Regulatory peptides from chromogranin A and secretogranin II: putative modulators of cells and tissues involved in inflammatory conditions. Regul Pept 165: 45-51, 2010.

35. May CL and Kaestner KH: Gut endocrine cell development. Mol Cell Endocrinol 323: 70-75, 2010.

36. Sandström O and El-Salhy M: Ageing and endocrine cells of human duodenum. Mech Ageing Dev 108: 39-48, 1999.

37. El-Salhy M: Ghrelin in gastrointestinal diseases and disorders: A possible role in the pathophysiology and clinical implications (Review). Int J Mol Med 24: 727-732, 2009.

38. Tolhurst G, Reimann F and Gribble FM: Intestinal sensing of nutrients. Handb Exp Pharmacol 209: 309-335, 2012.

39. Lee J, Cummings BP, Martin E, Sharp JW, Graham JL, Stanhope KL, Havel PJ and Raybould HE: Glucose sensing by gut endocrine cells and activation of the vagal afferent pathway is impaired in a rodent model of type 2 diabetes mellitus. Am J Physiol Regul Integr Comp Physiol 302: R657-R666, 2012.

40. Parker HE, Reimann F and Gribble FM: Molecular mechanisms underlying nutrient-stimulated incretin secretion. Expert Rey Mol Med 12: e1, 2010.

41. Raybould HE: Nutrient sensing in the gastrointestinal tract: Possible role for nutrient transporters. J Physiol Biochem 64: 349-356, 2008.

42. San Gabriel A, Nakamura E, Uneyama H and Torii K: Taste, visceral information and exocrine reflexes with glutamate through umami receptors. J Med Invest 56 (Suppl): 209-217, 2009. 
43. Rudholm T, Wallin B, Theodorsson E, Näslund E and Hellström PM: Release of regulatory gut peptides somatostatin neurotensin and vasoactive intestinal peptide by acid and hyperosmolal solutions in the intestine in conscious rats. Regul Pept 152: 8-12, 2009.

44. Sternini C, Anselmi L and Rozengurt E: Enteroendocrine cells: a site of 'taste' in gastrointestinal chemosensing. Curr Opin Endocrinol Diabetes Obes 15: 73-78, 2008.

45. Sternini C: Taste receptors in the gastrointestinal tract. IV. Functional implications of bitter taste receptors in gastrointestinal chemosensing. Am J Physiol Gastrointest Liver Physiol 292: G457-G461, 2007.

46. Buchan AM: Nutrient tasting and signaling mechanisms in the gut III. Endocrine cell recognition of luminal nutrients. Am J Physiol 277: G1103-G1107, 1999.

47. Montero-Hadjadje M, Elias S, Chevalier L, Benard M, Tanguy Y, Turquier V, Galas L, Yon L, Malagon MM, Driouich A, et al: Chromogranin A promotes peptide hormone sorting to mobile granules in constitutively and regulated secreting cells: role of conserved $\mathrm{N}$ - and C-terminal peptides. J Biol Chem 284 12420-12431, 2009.

48. Shooshtarizadeh P, Zhang D, Chich JF, Gasnier C, Schneider F, Haïkel Y, Aunis D and Metz-Boutigue MH: The antimicrobial peptides derived from chromogranin/secretogranin family, new actors of innate immunity. Regul Pept 165: 102-110, 2010.
49. El-Salhy M, Hatlebakk JG, Gilja $\mathrm{OH}$ and Hausken T: Irritable bowel syndrome: recent developments in diagnosis, pathophysiology, and treatment. Expert Rev Gastroenterol Hepatol 8: 435-443, 2014.

50. Höcker M and Wiedenmann B: Molecular mechanisms of enteroendocrine differentiation. Ann N Y Acad Sci 859: 160-174, 1998

51. Inokuchi H, Fujimoto $\mathrm{S}$ and Kawai K: Cellular kinetics of gastrointestinal mucosa, with special reference to gut endocrine cells. Arch Histol Jpn 46: 137-157, 1983.

52. El-Salhy M, Hatlebakk JG and Hausken T: Reduction in duodenal endocrine cells in irritable bowel syndrome is associated with stem cell abnormalities. World J Gastroenterol 21: 9577-9587, 2015.

53. El-Salhy M, Gilja OH, Gundersen D, Hatlebakk JG and Hausken T: Interaction between ingested nutrients and gut endocrine cells in patients with irritable bowel syndrome (Review). Int J Mol Med 34: 363-371, 2014. 